\title{
Gas for Dispersion for Injection Dosage Form
}

National Cancer Institute

\section{Source}

National Cancer Institute. Gas for Dispersion for Injection Dosage Form. NCI Thesaurus.

Code C149526.

Sterile preparation consisting of a gas that is intended to be mixed with the specified liquid to obtain a dispersion of the gas in the liquid, which is intended for administration by injection. 